\title{
Finite element analysis and optimization of a mono parabolic leaf spring using CAE software
}

\author{
Krishan Kumar $^{\mathrm{a}^{*}}$ and M. L. Aggarwal ${ }^{\mathrm{b}}$
}

\begin{abstract}
${ }^{a}$ Assistant Professor, Department Of Mechanical Engineering, YMCA University Of Science \& Technology, Faridabad, (HR.), India ${ }^{b}$ Professor, Department Of Mechanical Engineering, YMCA University Of Science \& Technology, Faridabad, (HR.), India

\begin{tabular}{l}
\hline A R T I C L E I N F O \\
\hline Article history: \\
Received October 6, 2014 \\
Accepted 2 February 2015 \\
Available online \\
2 February 2015 \\
\hline Keywords: \\
Finite Element Analysis \\
CAE \\
Leaf Spring \\
EN45A \\
GRP
\end{tabular}
\end{abstract}

\section{Introduction}

CAE software has been a popular tool to analyze the robustness and performance of components and assemblies. The finite element analysis (FEA) is a computing method implemented to find approximate solutions to the boundary value problems in engineering. It applies a numerical techniques named the finite element method (FEM). The component is modelled based on FEA using the discrete building blocks named elements. Each element contains some equations, which explain how it responds to certain loads. The sum of the response for all the elements in the model yields the total response of the design. CAE depends on actual assumptions of the assembly, which plays as input data. The component selected for this work is a parabolic leaf spring, which locates widespread application in

* Corresponding author. Tel: +919896596710

E-mail addresses: er.krishanverma@yahoo.com (K. Kumar) 
automotive industry. Leaf springs also play essential role in whole automotive vehicle body. It is well recognized that springs are designed to absorb shocks so the strain energy of the material becomes an important factor in designing the springs. Automotive organizations have been interested in weight reduction of different components by the introducing new materials having better properties, optimization of design and better manufacturing processes. It can be considered that materials having lower modulus and density could have a bigger specific strain energy capacity. As the composite materials maintain more elastic strain energy storage capacity and higher strength-to-weight ratio compared with steel, the introduction of composite materials makes it possible to reduce the weight of the leaf spring without any reduction on load carrying capacity and stiffness. Therefore, analysis of composite material leaf springs has become necessity in demonstrating the comparative results with conventional steel leaf springs. Aggarwal and Chawla (2007) explained that fretting fatigue between leaves could be reduced by careful control of shot peening parameters. The bending strength of EN45A parabolic leaf spring is determined to be higher as compared with semi-elliptic leaf spring. Corvi (1990) investigated a PC program for the preliminary design of composite beams using composite mechanics and the finite element method (FEM). Applications to an automotive leaf spring have demonstrated the feasibility of applying the program as a tool in building the initial design considerations and in developing preliminary designs. Refngah et al. (2009) investigated fatigue life prediction based on FEA and variable amplitude loading (VAL). Service loading of parabolic spring has been gathered using data acquisition system and FEA was executed on the spring model so stress and damage distribution could be observed, and experimental works were executed to validate the FEA result. Shankar and Vijayarangan (2006) applied a computer algorithm for the design of constant cross-section leaf spring. They designed, fabricated and tested a single leaf with variable thickness of unidirectional glass fiber reinforced plastic with similar mechanical and geometrical properties to the multi-leaf spring. Kumar and Aggarwal (2013) performed FEA simulation for a three layers EN45A parabolic leaf spring and validate the CAE results with experimental results by comparing the maximum displacement, directional displacement, equivalent stress and weight of the assembly. Patnaik et al. (2012) performed an investigation on a parabolic leaf spring of a mini loader truck. The spring was analyzed by using load and the corresponding values of stress and displacement were computed. They detected camber and leaf span of a parabolic leaf spring for optimized stress and displacement value using artificial neural networks. Yadav et al. (2012) analyzed a leaf spring whose thickness was differed from the center to the outer side following a parabolic pattern. Initially the magnitude of stress pertaining to parabolic leaf spring was measured by finite element method and then the approach to minimizing the stress was executed effectively with help of local algorithm for constants and priorities. Jayaswal and Kushwah (2012) discussed practical means of facilitating participatory steps executed in productivity enhancement with the emphasis on rejection minimization programs in parabolic Leaf Spring Manufacturing Unit in India. They discussed various methods for productivity improvement with the emphasis on reduction of rejections in terms of end gap and camber less in leaf spring in parabolic leaf spring manufacturing. Patunkar and Dolas (2011) applied modelling and analysis of composite mono leaf spring and compared its results. Kumar and Vijayarangan (2007) explained static and fatigue analysis of steel leaf spring and composite multi leaf spring made up of glass fiber reinforced polymer based on life data analysis. The dimensions of an existing conventional steel leaf spring of a light commercial vehicle were taken and verified by design calculations. The design constraints were stresses and deflections. Dewangan et al. (2012) explained basic structure, stress characteristics, engineering finite element modelling for investigating high stress zones. The equivalent von-misses stresses were plotted for the parabolic leaf spring. Patel et al. (2012) reviewed the design, analysis and fabrication of composite leaf spring through the literature survey. They tried to see the performance of epoxy glass fiber reinforced materials used in leaf spring by predicting fatigue life. Yu and Kim (1988) studied fundamental properties of the dimensioning of the double tapered FRP leaf spring. Prototype longitudinal type double tapered leaf springs to replace four leaf steel springs were made from glass fiber and epoxy. Prototype GRP leaf springs indicated a superior endurance and fail-safe characteristics. From the above literature we may conclude that CAE has become an important technology with benefits such as lower costs and a shortened design cycle. In future CAE system will 
be major information provider to assist design professionals in decision making. The objective of present work is to analyze a mono parabolic leaf spring by using CAE tools. The primary objective is on comparison of the optimized model with the conventional one by considering displacement, equivalent stress and weight.

\section{Material properties and design specifications}

\subsection{Material Properties}

The material of conventional model is EN45A spring steel having chemical composition by \% weight is $0.61 \mathrm{C}, 1.8 \mathrm{Si}, 0.79 \mathrm{Mn}, 0.02 \mathrm{~S}, 0.024 \mathrm{P}$, with unidirectional or isotropic behavior with respect to material properties which are shown in the Table 1. While on the other hand Glass Reinforced Plastics (GRP) is a composite material in which the volume fraction of glass fiber is $48 \%$. It is assembled using knitting machinery to form a unidirectional glass tape of constant width. It consists of 97\% glass in longitudinal direction and 3\% in transverse direction. The material properties of the composite are measured at the Institute of Polymer Mechanics in Latvia (see Table 2). The low density and high elastic strain of the composite provides high specific strain energy capacity. So the material properties of GRP are as shown in table below.

Table 1

Material Properties of Steel (EN45A)

\begin{tabular}{ll}
\hline Parameter & Steel \\
\hline Nature & Isotropic \\
Material selected & EN45A \\
Young's Modulus, E & $2.1 \times 10^{5} \mathrm{~N} / \mathrm{mm}^{2}$ \\
Poisson's Ratio & 0.266 \\
BHN & $400-425$ \\
Tensile strength-Ultimate & $1272 \mathrm{MPa}$ \\
Tensile strength-Yield & $1158 \mathrm{MPa}$ \\
Density & $0.00000785 \mathrm{~kg} / \mathrm{mm}^{3}$ \\
\hline
\end{tabular}

Table 2

Material Properties of GRP

\begin{tabular}{ll}
\hline Parameter & GRP \\
\hline Nature & Orthotropic \\
Young's Modulus, $\mathrm{E}_{\mathrm{xx}}$ & $38000 \mathrm{MPa}$ \\
\hline Young's Modulus, $\mathrm{E}_{\mathrm{yy}}$ & $13000 \mathrm{MPa}$ \\
\hline Young's Modulus, $\mathrm{E}_{\mathrm{zz}}$ & $13000 \mathrm{MPa}$ \\
Poisson's Ratio, $v_{\mathrm{xy}}$ & 0.31 \\
Poisson's Ratio, $v_{\mathrm{yz}}$ & 0.05 \\
Poisson's Ratio, v $v_{\mathrm{zx}}$ & 0.31 \\
Modulus of Rigidity, $\mathrm{G}_{\mathrm{xy}}$ & $1000 \mathrm{MPa}$ \\
Modulus of Rigidity, $\mathrm{G}_{\mathrm{yz}}$ & $16 \mathrm{MPa}$ \\
Modulus of Rigidity, $\mathrm{G}_{\mathrm{zx}}$ & $60 \mathrm{MPa}$ \\
Mass density & $0.00000185 \mathrm{~kg} / \mathrm{mm}^{3}$ \\
\hline Tensile strength-Yield & $900 \mathrm{MPa}$ \\
\hline
\end{tabular}

\subsection{Design Specifications}

The geometrical specification of leaf spring are as follows, 


$$
\begin{aligned}
& \text { Span length }=940 \mathrm{~mm} \text {, Seat Length }=100 \mathrm{~mm}, \\
& \text { Number of leaf }=1 \text {, Rated load }=1800 \mathrm{~N}, \\
& \text { Width of leaf }=60 \mathrm{~mm} \text {, } \\
& \text { Centre Rubber Pad }=100 \mathrm{~mm} \text { X } 50 \mathrm{~mm} \mathrm{X} \mathrm{5mm,} \mathrm{Camber}=36 \mathrm{~mm} .
\end{aligned}
$$

\section{CAD modeling and FEA}

CAD modeling software is associated with the specialized job of 3D-modeling. CAD modelling of this Mono Leaf Spring is executed by applying CATIA V5 R17 software. CATIA is having special capabilities in creating surface design to construct typical surfaces, which are later converted into solid models. Solid model of all parts of the structures are then assembled to make a complete structure. The process of assembly is very much analogous to general process of fabricating structures while real production. The CAD model of mono leaf spring applied for FE Analysis is demonstrated in Fig. 1.

A stress-deflection analysis is executed by applying FEA and the complete procedure of analysis has been performed using ANSYS workbench. To build FEA, the general process of FEM should be clear.

Finite Element method simulates a physical part or assembly's behavior by dividing the geometry of the part into a number of elements of standard shapes, applying loads and constraints, then calculating variables of interest - deflection, stresses, temperature, pressures etc. The behavior of an individual element is usually explained by a relatively simple set of equations. Just as the set of elements would be joined together to construct the whole structure, the equation explaining the behaviors of the individuals elements are joined into a set of equations, represent the behaviors of the whole structure. A finite element program takes the elements defined earlier, lists the equations for each unknown value, puts them together as a matrix equation, and then solves all these for the values of the unknown parameters. The equilibrium equation is of the form:

$[\mathbf{K}]\{\mathbf{u}\}=\{\mathbf{f}\}$

Since it is analogous to the equations of spring deflection, $\mathbf{K}$ is often called stiffness matrix, $\mathbf{u}$ is called the deformation vector, and $\mathbf{f}$ is called the load vector. $\mathbf{K}$ is a square matrix, with one row and column for each unknown variable in the problem definition. To build finite element analysis, the general process of FEA is divided into three main phases, preprocessor, solution, and postprocessor.

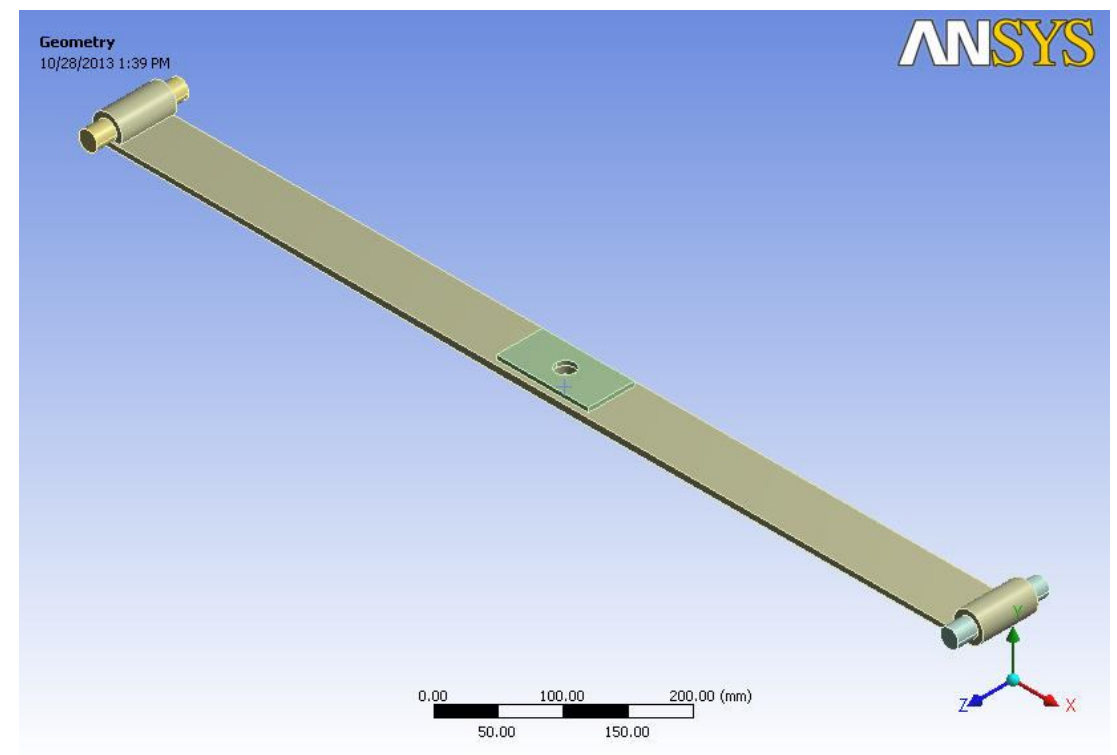

Fig. 1. CAD Model in ANSYS 
Meshing of the model is executed in which model is discretized into finite number of elements and nodes as in Fig. 2. This mesh along with material properties is used to mathematically represent the stiffness and mass distribution of the structure.

Table 3

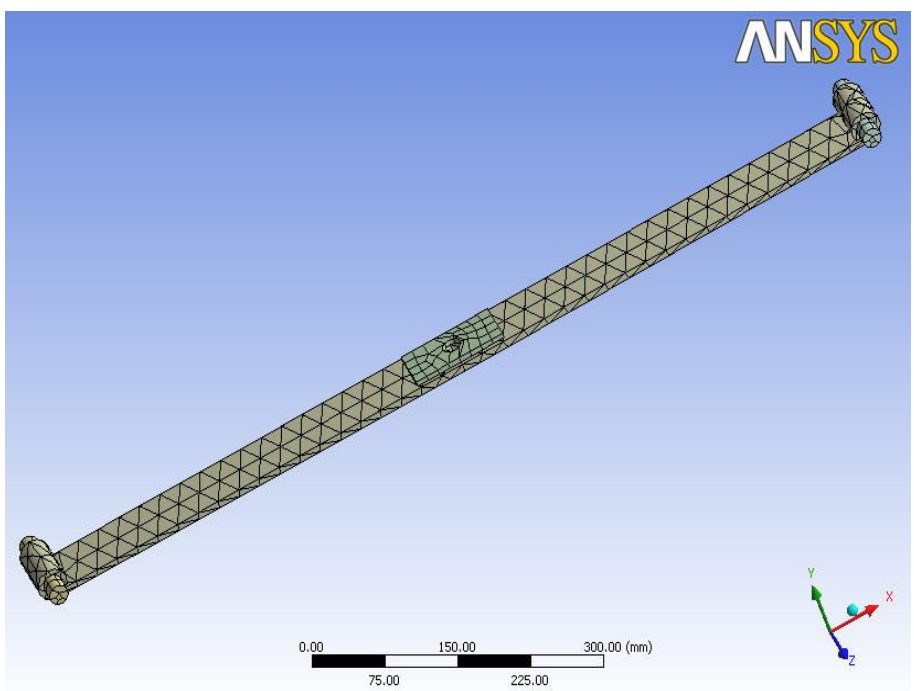

Details of Steel Model

\begin{tabular}{ll}
\hline Object Name & Geometry \\
State & Fully Defined \\
\hline $\begin{array}{l}\text { Definition } \\
\text { Length Unit }\end{array}$ & Meters \\
Element Control & Program Controlled \\
\hline Bounding Box & \\
Length X & $972 . \mathrm{mm}$ \\
Length Y & $78 . \mathrm{mm}$ \\
Length Z & $100.32 \mathrm{~mm}$ \\
\hline Properties & \\
Volume & $5.3444 \mathrm{e}+005 \mathrm{~mm}^{3}$ \\
Mass & $4.0607 \mathrm{~kg}$ \\
\hline Statistics & \\
Active Bodies & 4 \\
Nodes & 2771 \\
Elements & 877 \\
\hline
\end{tabular}

Fig. 2: Meshing showing nodes \& elements

The boundary condition is the collection of various forces, pressure, velocity, supports, constraints and every condition required for complete analysis. Applying boundary condition is one of the most typical processes of analysis. A special care is required while assigning loads and constraints to the elements.

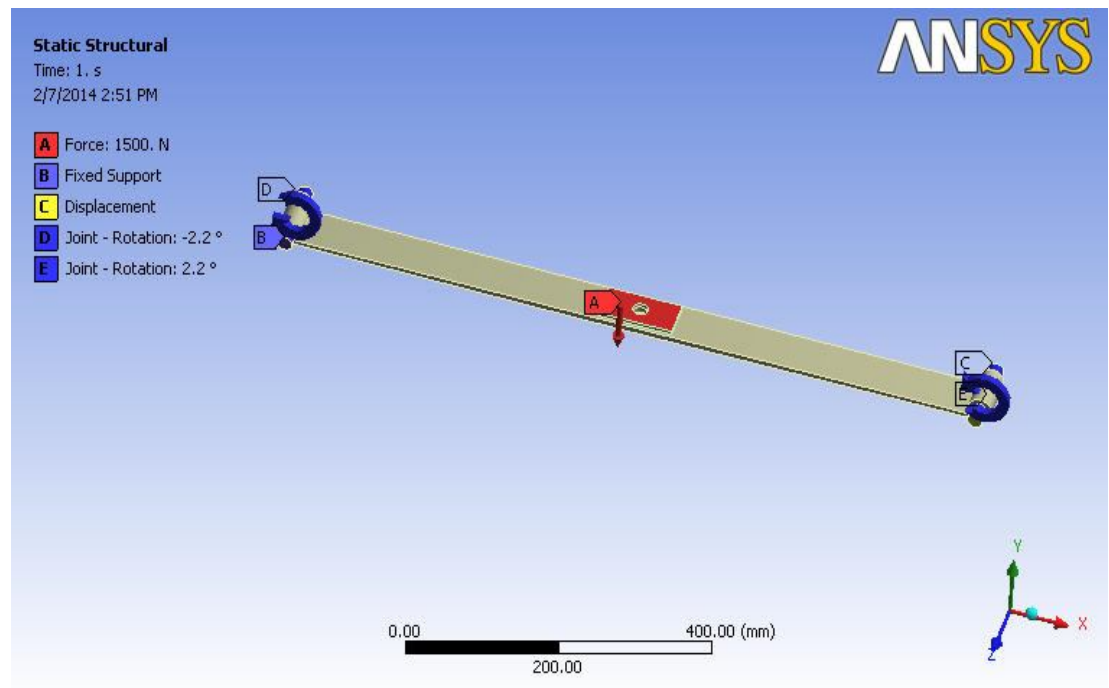

Fig. 3. Boundary Conditions

Boundary condition of the leaf spring involves the fixation of one of the revolute joint and applying displacement support at the other eye end of leaf spring. A joint rotation of $2.2^{\circ}$ has been taken for both revolute joints considering the no load camber. Loading conditions involves applying a load at the 
center of the leaf. As per specifications the spring is drawn at flat condition, therefore the load is applied in downward direction to achieve initial no load condition. The model under defined boundary conditions is shown in Fig. 3. The leaf having two eye ends make revolute type of joint with pin inserted at both ends. Table 4 demonstrates the definition of both of the revolute joints. The details of load applied and different supports at both ends are defined in the Table 5 and joint rotation in Table 6.

Table 4

\begin{tabular}{|c|c|}
\hline \multicolumn{2}{|l|}{ Joint Details } \\
\hline Object Name & Revolute - Part23.2 To Part1.1.2 \\
\hline State & Fully Defined \\
\hline \multicolumn{2}{|l|}{ Definition } \\
\hline Connection Type & Body-Body \\
\hline Type & Revolute \\
\hline Suppressed & No \\
\hline \multicolumn{2}{|l|}{ Reference } \\
\hline Scoping Method & Geometry Selection \\
\hline Scope & 2 Faces \\
\hline Body & Part23.2 \\
\hline Coordinate System & Reference Coordinate System \\
\hline \multicolumn{2}{|l|}{ Mobile } \\
\hline Scoping Method & Geometry Selection \\
\hline Scope & 1 Face \\
\hline Body & Part1.1.2 \\
\hline Initial Position & Unchanged \\
\hline
\end{tabular}

\section{Table 5}

Loading \& Support Details

\begin{tabular}{lccc}
\hline Object Name & Force & Fixed Support & Displacement \\
State & & Fully Defined & \\
\hline $\begin{array}{l}\text { Scope } \\
\text { Scoping Method }\end{array}$ & Geometry Selection & \\
Geometry & 1 Face & 2 Faces \\
\hline $\begin{array}{l}\text { Definition } \\
\text { Define By }\end{array}$ & Components & Components \\
Type & Force & Fixed Support & Displacement \\
Coordinate System & Global Coordinate System & & Global Coordinate System \\
X Component & $0 . \mathrm{N}$ (ramped) & Free \\
Y Component & $-1500 . \mathrm{N}$ (ramped) & & 0. mm (ramped) \\
Z Component & $0 . \mathrm{N}$ (ramped) & & 0. mm (ramped) \\
Suppressed & & No & \\
\hline
\end{tabular}

\section{Table 6}

Camber Detail

\begin{tabular}{lccc}
\hline Object Name & Joint - Rotation & Joint - Rotation \\
State & & Fully Defined & \\
\hline Scope & Revolute - Part23.2 To Part1.1.2 & & Revolute - Part23.1 To Part1.1.2 \\
\hline Joint & & Rotation Z & \\
\hline Definition & & Rotation & \\
DOF & & & $2.2^{\circ}$ (ramped) \\
Type & $-2.2^{\circ}$ (ramped) & No & \\
Magnitude & & & \\
Suppressed & & & \\
\hline
\end{tabular}

\section{Results and discussions}

The contours of displacement and Von-mises stress for the steel leaf spring have been shown in Figs. 4 and 5. 


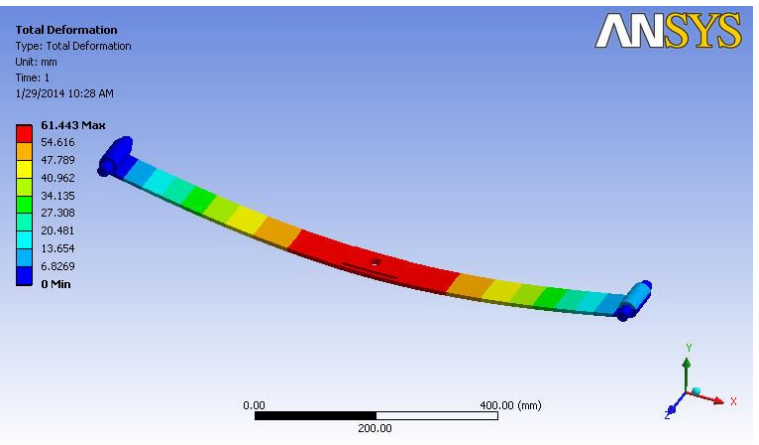

Fig. 4. Deflection in steel leaf spring

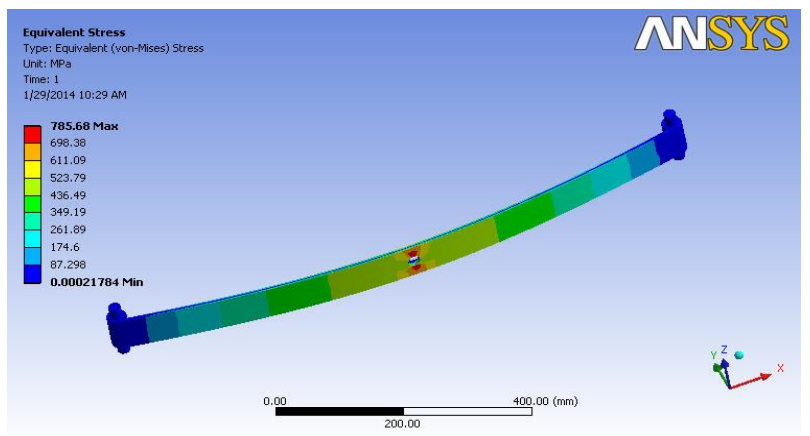

Fig. 5. Von-mises stress in steel leaf spring

Figs. 6 and 7 also shows the FEA results for the GRP leaf spring.

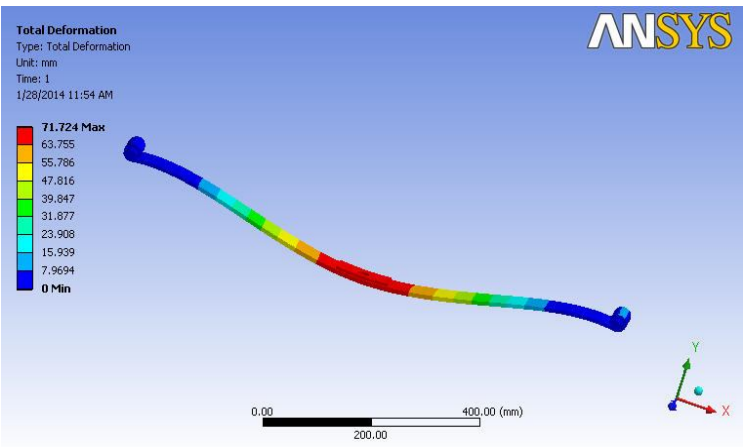

Fig. 6. Deflection in GRP leaf spring

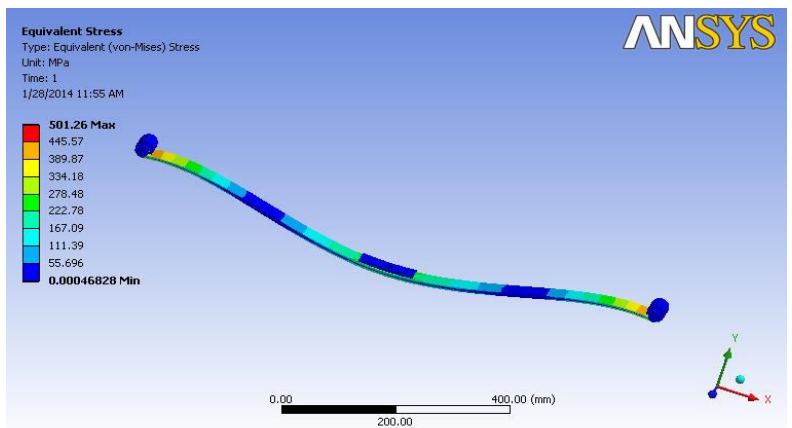

Fig. 7. Von-mises stress in leaf spring

From the FEA result data a comparison of both i.e. steel and GRP Leaf spring may be summarized as the following Table (Table 7):

Table 7

Result Comparisons

\begin{tabular}{lll}
\hline Parameters & Steel Leaf Spring & GRP Leaf Spring \\
\hline Normal Static Load & $1500 \mathrm{~N}$ & $1500 \mathrm{~N}$ \\
Deflection & $61.443 \mathrm{~mm}$ & $71.724 \mathrm{~mm}$ \\
Von-Mises Stress & $785.68 \mathrm{MPa}$ & $501.26 \mathrm{MPa}$ \\
Mass & $4.0607 \mathrm{~kg}$ & $1.3716 \mathrm{~kg}$ \\
\hline
\end{tabular}

From the above comparison Table it has been observed that when a mono steel parabolic leaf and a mono GRP parabolic leaf analyzed with FEA, for the same static load and boundary conditions, the deflection in the case of steel is $61.443 \mathrm{~mm}$ while in case of GRP it is $71.724 \mathrm{~mm}$ which shows that a composite leaf has a little bit more deflection in comparison to steel. On the other hand the value of von-mises stress has been decreased from the $785.68 \mathrm{MPa}$ to $501.26 \mathrm{MPa}$ in steel and GRP leafs respectively. At the same time a large weight reduction is also experienced i.e. weight in case of steel is $4.0607 \mathrm{~kg}$ while of GRP leaf is $1.3716 \mathrm{~kg}$.

\section{Conclusion}

From the results obtained from FE Analysis, some discussions have been made and it will be concluded that, 
1. When steel leaf spring is replaced by composite material (GRP), the deflection of the leaf has been increased by a small amount which is acceptable.

2. The Von-mises stress in case of GRP Leaf spring is decreased by large amount which makes it much more beneficial to the design point of view.

3. When comparing steel \& GRP parabolic leaf spring, there is a material saving of $66.12 \%$ by weight which also proves it an optimized design.

Computer Aided FEA has become an important technology with benefits such as lower costs and a shortened design cycle. In future it will be the major information provider to help design professionals in decision making.

\section{References}

Aggarwal, M. L., \& Chawla, P. S. (2007). Issues in fretting fatigue design of shot peened leaf springs. Indian Journal of Engineering and Materials Sciences, 14(6), 414.

Aggarwal, M. L., Agrawal, V. P., \& Khan, R. A. (2006). A stress approach model for predictions of fatigue life by shot peening of EN45A spring steel. International journal of fatigue, 28(12), 18451853.

Aggarwal, M. L., Khan, R. A., \& Agrawal, V. P. (2006). Effect of surface roughness on the fretting fatigue behaviour of EN45A spring steel. Proceedings of the Institution of Mechanical Engineers, Part B: Journal of Engineering Manufacture, 220(8), 1325-1331.

Corvi, A. (1990). A preliminary approach to composite beam design using FEM analysis. Composite structures, 16(1), 259-275.

Dewangan, R. K., Patnaik, M., \& Yadav, N. (2012). Minimization of stress of a parabolic leaf spring by simulated annealing algorithm. International Journal of Engineering research and Applications, 2(4), 457-460.

Kumar, K., \& Aggarwal, M. L. (2013). Computer aided FEA simulation of EN45A parabolic leaf spring. International Journal of Industrial Engineering Computations, 4(2), 297-304.

Kumar, M. S., \& Vijayarangan, S. (2007). Analytical and experimental studies on fatigue life prediction of steel and composite multi-leaf spring for light passenger vehicles using life data analysis. Materials science, 13(2), 141-146.

Patel, S. K., Jain, A. K., \& Gandhi, P. (2012). A Review of Effect of Material on Fatigue Life of Leaf Spring. VSRD International journal of mechanical, automobile and production engineering, 2(4), 161-165.

Patnaik, M., Koushik, L. P., \& Mathew, M. (2012). Determination of camber and leaf span of a parabolic leaf spring for optimized stress and displacement using artificial neural networks. International Journal of Modern Engineering Research, 2(4), 2771-2773.

Patunkar, M. M., \& Dolas, D. R. (2011). Modelling and Analysis of Composite leaf spring under the static load condition by using FEA. International Journal of Mechanical \& Industrial Engineering, 1(1-2011), 1-4.

Refngah, F. A., Abdullah, S., Jalar, A., \& Chua, L. B. (2009). Life assessment of a parabolic spring under cyclic strain loading. European Journal of Science Research, 28, 351-353.

Shankar, G. S. S., \& Vijayarangan, S. (2006). Mono composite leaf spring for light weight vehicledesign, end joint analysis and testing. Materials science, 12(3), 220-225.

Yadav, N., Dewangan, R., \& Patnaik, M. (2012). Minimization of stress in a parabolic leaf spring by local algorithm for constant \& priorities. International Journal of Engineering Research and Applications, 2(4), 1897-1899.

Yu, W. J., \& Kim, H. C. (1988). Double tapered FRP beam for automotive suspension leaf spring. Composite structures, 9(4), 279-300. 